\title{
THE APPEARANCE OF THE INDUCED DORMANCY IN SEEDS OF SOME Umbelliferae VEGETABLE CROPS UNDER THE EFFECT OF ALLELOPATHIC SUBSTANCES
}

\section{A.F. BUKHAROV, D.N. BALEEV}

All-Russian Research Institute for Vegeculture, Federal Agency of Scientific Organizations, 500, Vereya, Ramenskii Region, Moscow Province, 140153 Russia, e-mail baleev.dmitry@yandex.ru Received March 3, 2016

\section{Abstract}

Allelopathic effects in plants are due to a combination of many adaptive and environmental factors having evolutionary and economic importance. Currently the investigations on the effects of allelopathic substances on seed germination in order to develop new environmentally friendly approach to plant protection against weeds are in progress. The main goal of our experiments was to examine the peculiarities of the seed dormancy induced under the influence of an extract from seeds of dill (Anethum graveolens L.) variety Kentavr and specific overcoming of the dormancy in various vegetable crops - carrot (Daucus carrota L.) variety Rogneda, root parsley (Petroselinum crispum (Mill.) Nyman ex A.W. Hill.) variety Lyubasha, celery root (Apium graveolens L.) variety Kupidon, lavage (Levisticum officinale W.D.J. Koch) variety Don Zhuan, coriander (Coriandrum sativum L.) variety Yantar', and parsnip (Pastinaca sativa L.) variety Kulinar. The seeds of tested crops were treated with $15 \%$ aqueous extract from dill seeds at $23{ }^{\circ} \mathrm{C}$ for 0 (control), 5 and 20 days in the dark. A germination of the treated seed germination was studied in dynamics at different temperature conditions $-20{ }^{\circ} \mathrm{C}$ (control); $3{ }^{\circ} \mathrm{C}$; and $3{ }^{\circ} \mathrm{C}$ ( 8 hours) $/ 20{ }^{\circ} \mathrm{C}$ (16 hours). We calculated $\mathrm{T}_{\mathrm{ip}}$ (initial period, i.e. the time prior to seed germination starts), $\mathrm{T}_{\text {wagt }}$ (the weighted average germination period, i.e. the time to reach maximum germination rate) and $\mathrm{T}_{50}$ (the time to reach $50 \%$ germination), measured the embryo length and calculated the temperature coefficient (Q10). It was shown the extract noticeably inhibited the embryo growth and seed germination in the studied crops. After exposure to allelopathic factors for 5 days the seeds of carrots, celery root, parsnip and coriander did not germinate at a standard temperature. The $\mathrm{T}_{\text {wagt }}$ values exceeded the control by 229-328 \%, and the $\mathrm{T}_{50}$ values were $310-379 \%$ higher. In dill, parsley root and lovage the germinated seeds accounted for 42,52 and $23 \%$, respectively. After a 20 day exposure to the allelopathic factor the seeds of celery root, carrots, parsnip and coriander did not germinate whereas in dill and lovage seeds germination delayed by 21 and 22 days. Increasing exposure time resulted in a reduced temperature coefficient $\left(\mathrm{Q}_{10}\right)$ for embryo growth at different temperatures. Low temperature including constant $3{ }^{\circ} \mathrm{C}$ and variable $\left(3 / 20^{\circ} \mathrm{C}\right)$ contributed to a partial recovery of these processes in the seeds pre-exposed to allelopathic factor. In this, the $\mathrm{T}_{\text {wagt }}$ and $\mathrm{T}_{50}$ increased by 11.7-35.3 days and 11.7-43.1 days, respectively, compared to control. Analysis of a combined effect of the allelopathic factor and temperature evidenced that the inhibition of seed germination influenced by the substances contained in the extract of dill seeds is due to the dormancy phenomenon.

Keywords: allelopathy, temperature, seed dormancy, seed germination, growth rate of the embryo, the temperature coefficient $\left(\mathrm{Q}_{10}\right)$

Allelopathy, based on the chemical interaction, is one of the oldest communications between biological objects, different organs, tissues and cells. Allelopathic interference of plants is caused by a combination of numerous permanent and transient biogenic factors [1], and has an adaptive, ecological, evolutionary and economic importance [2, 3]. Current studies show that allelopathy may be a part of a network of chemical communication [4], and perform a variety of functions, including protective ones [5, 6]. Both stimulatory and inhibitory effects of extracts from fruits, seeds and other plant organs have been established [7].

There are numerous reports on the effect of various substances on seed germination [8, 9]. A study of allelopathic agents will allow to develop novel 
eco-friendly methods for weed control $([10,11]$. For example, an extract from seeds of Myrica gale L. exhibits an inhibitory effect, and a substance called Myrigalone A affects the gibberellin biosynthesis and signaling systems of germinating seeds $[12,13]$. Metabolites interrupt the germination of seeds and have a negative effect on growth, respiration and protein synthesis [14, 15].

A group of substances (strigolactones) discovered in the root exudates is capable of stimulating germination of parasitic weed species, such as Orobanche and Striga. These substances are considered a new class of hormones $[16,17]$ that affect the balance of abscisic acid and gibberellin which are responsible for seed dormancy [18].

In our previous studies, we described the effect of a $15 \%$ extract of dill seeds on the dormancy induction in tester seeds of mustard greens and Japanese mustard (Mizuna) [19].

In this paper, for the first time we demonstrated that the effect of the dill seed extract led to a delay (up to complete inhibition) in the germination of seeds of vegetable crops in the Umbelliferae family. The induced dormancy is maintained for a long time even after seeds are transferred into standard conditions, however, it does not cause their death.

The aim of our study was to examine the peculiarities of seed dormancy induced by an extract from dill seeds, and the overcoming of the dormancy state in the Umbelliferae vegetable family

Techniques. We studied the seeds of dill (Anethum graveolens L.) variety Kentavr, carrot (Daucus carrota L.) variety Rogneda, root parsley (Petroselinum crispum (Mill.) Nyman ex A.W. Hill.) variety Lyubasha, celery (Apium graveolens L.) variety Kupidon, lovage (Levisticum officinale W.D.J Koch) variety Don Zhuan, coriander (Coriandrum sativum L.) variety Yantar', and parsnip (Pastinaca sativa L.) variety Kulinar.

To prepare an aqueous extract, $15 \mathrm{~g}$ of dill seeds were pounded in a mortar with pestle, followed by addition of distilled water $(100 \mathrm{ml})$, then infused for $1 \mathrm{~h}$, and then filtered through a paper filter. The seeds of the tested cultures were incubated in the extract at $23{ }^{\circ} \mathrm{C}$ in Petri dishes on filter paper with no exposure to light for 0 (control), 5 and 20 days. We repeated the experiment 3 times (using 1,000 seeds per each replication). After incubation the seeds were washed in water and germinated on filter paper with no exposure to light.

Seed germination was studied at $20^{\circ} \mathrm{C}$ (standard mode), $3{ }^{\circ} \mathrm{C}$, and $3{ }^{\circ} \mathrm{C}$ $(8 \mathrm{~h}) / 20^{\circ} \mathrm{C}(16 \mathrm{~h})$ temperature conditions. The following parameters were calculated: $\mathrm{T}_{\mathrm{ip}}$ - the time from seed layout up to the germination; $\mathrm{T}_{\mathrm{wagt}}-$ the weighted average germination period which can be considered as the number of days until the maximum germination rate $[20,21] ; \mathrm{T}_{50}-$ the time to reach the germination of $50 \%$ seeds [22-24], as well as the proportion of germinated seeds. The completion of seed germination was evaluated by their protrusion [25]. We repeated the experiment 3 times (using 100 seeds per each replication).

The length of the embryo was measured under a Levenhuk 670T (Levenhuk, USA) microscope equipped with the digital microscope eyepiece camera DCM 300 MD (Microscope Digital, China), at $\times 40$, using the Scope Photo software (Image Software v. 3.1.386). The temperature coefficient $\left(\mathrm{Q}_{10}\right)$ of the embryo growth rate was calculated using the Van 't Hoff equation.

Statistical analysis was performed using the programming language $\mathrm{R}$ (i386 v.3.3.0).

Results. Within 20 days of incubation, the seeds of all studied crops did not germinate in the dill seed extract $(15 \%)$. In carrots and root parsley, after 18-20 day exposition, autolysis of a part of the seeds (20-40\%) occurred. The morphometric analysis showed no growth of the embryo. 
After being incubated for 5 days and then transferred to standard conditions $\left(20^{\circ} \mathrm{C}\right)$, the seeds of celery, parsnip, carrots and coriander did not germinate. The growth processes in the seeds of all the remaining crops gradually resumed, however, all parameters, characterizing the intensity of the growth processes, were higher in them than in control plants, indicating a slowdown in seed germination. Accordingly, $T_{i p}$ in dill, root parsley and lovage was 15-17 days which was 10-14 days longer than in control. The $\mathrm{T}_{\text {wagt }}$ value exceeded control by $229-328 \%$ and the $\mathrm{T}_{50}$ value by $310-379 \%$. Seeds of carrots, root parsley and parsnip did not germinate at $3{ }^{\circ} \mathrm{C}$ (see Table).

Low temperature $\left(3{ }^{\circ} \mathrm{C}\right)$ promoted (albeit with a delay) the germination of seeds of dill, lovage, celery and coriander. Seeds which suffered from the effects of the allelopathic factor for 5 days needed more time to germinate at a reduced temperature $\left(3^{\circ} \mathrm{C}\right)$. There was an increase by 11.7-35.3 days for $\mathrm{T}_{\text {wagt }}$ and by 11.7-43.1 days for $\mathrm{T}_{50}$, as compared to control, and by 9.8 and 2.8 days, respectively, when compared to standard conditions. The difference between $T_{\text {wagt }}$ and $\mathrm{T}_{50}$ values increased concurrently up to 5.8 to 9.2 days.

The indicators characterizing the rate of seed germination in the Umbelliferae vegetable crops affected by the allelopathic stress (incubation in the $15 \%$ extract of dill seeds) and specific germination conditions (lab experiments)

\begin{tabular}{l|l|c|c|c|c|c|c}
\hline & Duration of & \multicolumn{3}{c|}{$\mathrm{T}_{\text {wagt }}$, days } & \multicolumn{3}{c}{$\mathrm{T}_{50}$, days } \\
\cline { 3 - 8 } Crops & $\begin{array}{l}\text { incubation, } \\
\text { days }\end{array}$ & $20{ }^{\circ} \mathrm{C}$ & $3{ }^{\circ} \mathrm{C}$ & $3 / 20{ }^{\circ} \mathrm{C}$ & $20{ }^{\circ} \mathrm{C}$ & $3{ }^{\circ} \mathrm{C}$ & $3 / 20{ }^{\circ} \mathrm{C}$ \\
\hline Carrot, Daucus & 0 (control) & $7.5 \pm 0.5$ & $16.7 \pm 0.6$ & $10.2 \pm 0.5$ & $8.5 \pm 0.6$ & $18.5 \pm 0.6$ & $11.9 \pm 1.0$ \\
carrota L., Rogneda var. & 5 & - & - & $35.6 \pm 1.2$ & - & - & $44.3 \pm 1.8$ \\
& 20 & - & - & $38.7 \pm 2.0$ & - & - & $49.1 \pm 2.7$ \\
Anethum & 0 (control) & $7.9 \pm 0.7$ & $14.3 \pm 1.1$ & $10.3 \pm 1.0$ & $90 \pm 0.4$ & $20.1 \pm 2.3$ & $10.0 \pm 1.0$ \\
graveolens L. dill, Kentavr & 5 & $25.9 \pm 1.6$ & $26.0 \pm 0.7$ & $27.7 \pm 1.7$ & $34.1 \pm 3.8$ & $31.8 \pm 2.0$ & $51.2 \pm 7.9$ \\
var. & 20 & $37.5 \pm 2.0$ & $44.7 \pm 1.2$ & $33.8 \pm 1.0$ & $45.3 \pm 4.1$ & $56.2 \pm 2.6$ & $50.4 \pm 7.0$ \\
Apium graveolens L. celery, & 0 (control) & $11.0 \pm 0.6$ & $23.5 \pm 1.0$ & $11.2 \pm 0.7$ & $14.0 \pm 0.3$ & $26.9 \pm 1.0$ & $12.2 \pm 0.5$ \\
Kupidon var. & 5 & - & $58.8 \pm 1.3$ & $48.0 \pm 0.8$ & - & $70.0 \pm 4.5$ & $60.1 \pm 4.9$ \\
& 20 & - & $68.2 \pm 2.0$ & $53.3 \pm 3.1$ & - & $89.8 \pm 5.3$ & $75.1 \pm 5.4$ \\
Root parsley, & 0 (control) & $10.4 \pm 0.6$ & $20.0 \pm 1.0$ & $90 \pm 0.4$ & $12.5 \pm 1.6$ & $23.1 \pm 1.2$ & $10.5 \pm 0.6$ \\
Petroselinum crispum (Mill.) & 5 & $21.9 \pm 0.5$ & - & $20.3 \pm 1.4$ & $27.3 \pm 2.6$ & - & $28.9 \pm 2.9$ \\
Nyman ex A.W. Hill., & 20 & $29.1 \pm 1.1$ & - & $27.2 \pm 1.0$ & $40.1 \pm 3.0$ & - & $35.1 \pm 2.0$ \\
Lyubasha var. & & & & & & & \\
Parsnip, Pastinaca & 0 (control) & $16.0 \pm 1.0$ & $26.7 \pm 0.5$ & $13.3 \pm 0.7$ & $21.5 \pm 2.0$ & $30.8 \pm 1.0$ & $15.3 \pm 2.5$ \\
sativa L., Kulinar var. & 5 & - & - & $43.8 \pm 2.9$ & - & - & $55.0 \pm 7.1$ \\
& 20 & - & - & $52.4 \pm 0.6$ & - & - & $64.2 \pm 1.4$ \\
Lovage, Levisticum officinale & 0 (control) & $9.1 \pm 0.7$ & $12.7 \pm 0.8$ & $11.0 \pm 0.2$ & $11.9 \pm 2.0$ & $16.9 \pm 1.1$ & $15.0 \pm 0.4$ \\
W.D.J. Koch, & 5 & $20.8 \pm 1.4$ & $30.6 \pm 1.0$ & $20.5 \pm 2.0$ & $37.0 \pm 7.1$ & $39.8 \pm 4.0$ & $27.6 \pm 4.4$ \\
Don Zhuan var. & 20 & $29.5 \pm 1.0$ & $42.2 \pm 2.0$ & $42.4 \pm 2.7$ & $60.5 \pm 11.9$ & $57.4 \pm 6.5$ & $60.1 \pm 4.0$ \\
Coriander, Coriandrum sa- & 0 (control) & $9.7 \pm 0.3$ & $21.8 \pm 1.2$ & $15.0 \pm 0.7$ & $13.0 \pm 1.0$ & $28.2 \pm 1.1$ & $21.7 \pm 1.4$ \\
tivum L., Yantar' var. & 5 & - & $46.0 \pm 1.2$ & $44.2 \pm 4.3$ & - & $62.1 \pm 3.7$ & $62.8 \pm 6.4$ \\
& 20 & - & $71.9 \pm 0.8$ & $54.0 \pm 3.0$ & - & $95.0 \pm 7.0$ & $67.2 \pm 2.7$
\end{tabular}

Note. $\mathrm{T}_{\text {wagt }}-$ the weighted average germination period; $\mathrm{T}_{50}-$ the time to reach the germination of $50 \%$ seeds. Dashes indicate there was no germination.

Variable temperature profile had a positive effect as compared to the standard mode, promoting the germination of all the studied crops. It reduced the negative effect of allelopathic factors. However, the $\mathrm{T}_{\text {wagt }}$ and $\mathrm{T}_{50}$ values, affected by the 5-day incubation, increased by329-429 \% and 372-492\%, respectively, as compared to the control.

After suffering exposure to the allelopathic factor for 20 days, the seeds germinated even more slowly. At a temperature of $20^{\circ} \mathrm{C}$, the seeds of celery, carrot, parsnip and coriander did not germinate. The germination of seeds of dill and lovage started with a delay by 21 and 22 days compared to control. $T_{\text {wagt }}$ increased up to 37.5 and 29.5 days, and $\mathrm{T}_{50}$ up to 45.3 and 60.5 days, which were, respectively, 20.4-29.6 and 36.3-48.6 days higher than in the control.

Seeds of dill and lovage germinated less actively at $3{ }^{\circ} \mathrm{C}$ (after incubation for 20 days) when compared to the standard conditions. The seeds of celery and 
coriander still began to germinate, although with a considerable delay (55 and 58 days), however, the $\mathrm{T}_{\text {wagt }}$ value was 68.2 and 71.9 days, respectively, and $\mathrm{T}_{50}$ reached 70.0 and 95.0 days. The seeds of parsnip and carrot were the only ones not germinated.

Under variable temperatures, seeds of all crops, exposed to the allelopathic factor for 20 days, germinated, however, the $T_{\text {wagt }}$ and $T_{50}$ values increased 4.0-4.2 times as compared to control.

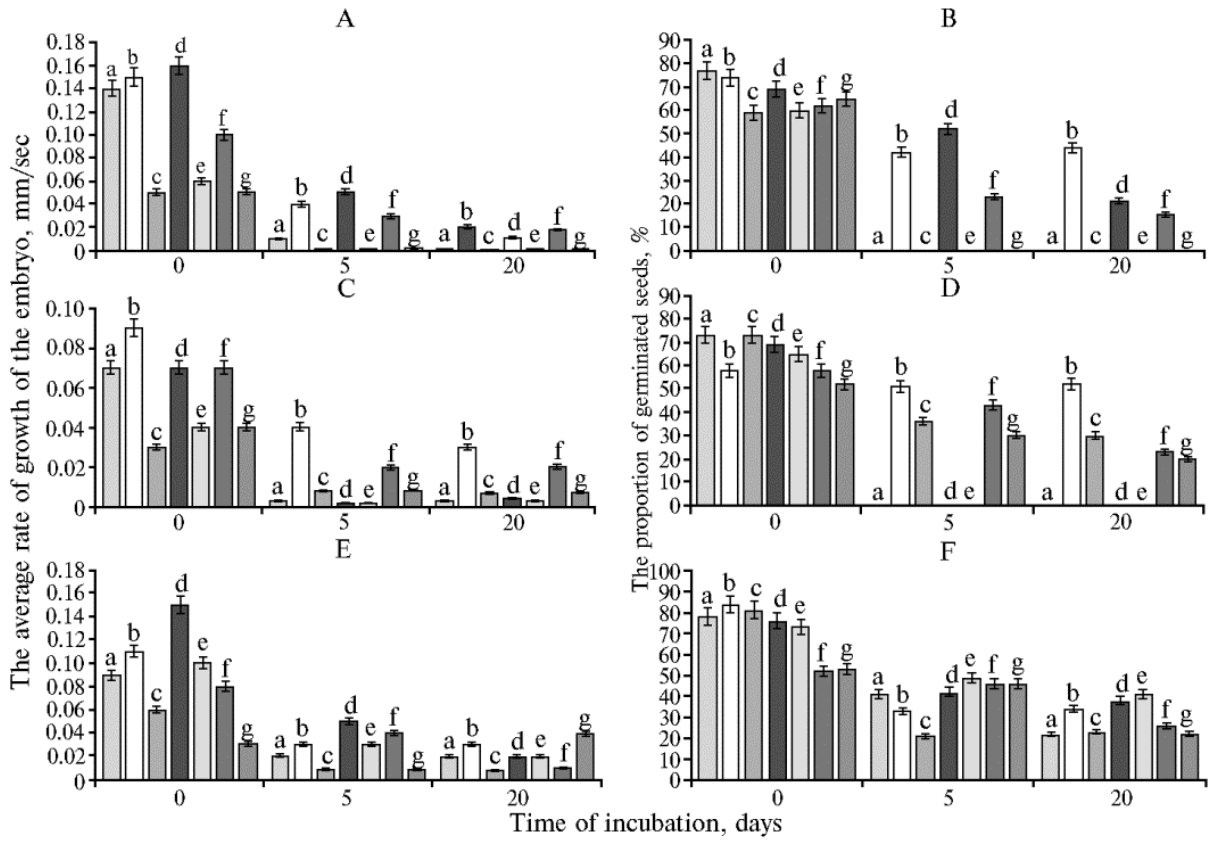

Fig. 1. The average rate of growth of the embryo (left) and the proportion of germinated seeds (right) in carrot (Daucus carrota L.) Rogneda var. (a); dill (Anethum graveolens L.) Kentavr var. (b); celery (Apium graveolens L.) Kupidon var. (c); root parsley (Petroselinum crispum (Mill.) Nyman ex A.W. Hill Lyubasha var. (d); parsnip (Pastinaca sativa L. ) Kulinar var. (e), lovage (Levisticum officinale W.D.J. Koch, Don Zhuan var. (f), coriander (Coriandrum sativum L.), Yantar' var. (g) depending on temperature and time of incubation in the $15 \%$ extract of dill seeds: $\mathrm{A}, \mathrm{B}-20{ }^{\circ} \mathrm{C}$ (standard mode), $\mathrm{C}, \mathrm{D}-3{ }^{\circ} \mathrm{C}, \mathrm{E}, \mathrm{F}-3 / 20^{\circ} \mathrm{C}$ (lab experiments).

When seeds were germinated post incubation at the constant positive temperature, the embryo growth rate steadily decreased with increasing stress period (Fig. 1). In control, the embryo in the seeds of dill, carrot, root parsley grew at a rate of $0.14-0.16 \mathrm{~mm} / \mathrm{day}$. After 5 days of incubation, the embryo growth rate reduced to $0.01-0.05 \mathrm{~mm} /$ day, and after 20 days down to $0.02 \mathrm{~mm} /$ day. The coriander embryo, which grew in the control at a rate of $0.15 \mathrm{~mm} /$ day, virtually ceased to grow with increasing incubation time.

One of the key endogenous factors affecting seed germination in crops of the Umbelliferae family is a morphological immaturity of the embryo [26, 27]. The immaturity occurs irrespective of time the seeds maturates on the mother plant. After seed separation, the full development of the embryo completes under adequate moisture and favorable temperatures [28]. This underlies special requirements when dealing with the seeds of the Umbelliferae family plants. To evaluate any changes occurring during their germination, it is insufficient to determine their dimensions and dry weight. Only the analysis of the continuous growth of seed morphological elements, primarily of the embryo, may reveal significant patterns. In celery and parsnip, the growth rate of the embryo was 0.05 and $0.06 \mathrm{~mm} /$ day in the control, while after even 5 day-exposure to the extract it decreased sharply down to $0.0007 \mathrm{~mm}$ /day. 
At $3{ }^{\circ} \mathrm{C}$, the average rate of the post incubation embryo growth in all the crops (except for parsley) was 30 to $60 \%$ higher than under the standard temperature conditions. However, the growth rate of the embryo linear size remained lower by 43-93\% as compared to control.

Under variable temperature conditions, an increase in the embryo growth rate by 20-92\% was observed in all crops as compared to the standard conditions, and only in carrot, coriander and parsley (by 11-96 \%) if compared to the constantly low temperature. However, it was impossible to completely overcome the negative effects of allelopathic stress with the variable temperature. The growth rate of the embryo was 300-330 \% lower than in control.

The temperature is known to be one of the most important abiotic factors that ensure exiting dormancy [29-31]. Exposure to low temperature activates the mechanisms promoting the onset of the gibberellin synthesis [32]. At low temperatures, the breakdown of storage compounds in the endosperm is activated and the synthesis in the embryo is stimulated in immature seeds, which are typical for the Umbelliferae vegetable family [33].

The inhibition of germination under the influence of the extract of dill seeds, which was observed in our experiments, appeared to result from the induced dormancy.

The proportion of germinated seeds for different crops varied depending on a combination of the studied factors. After exposure to the allelopathic agent for 5 days, no germinated seeds were observed at the standard temperatures in the carrots, celery, parsnip and coriander. The proportion in dill, root parsley and lovage was 42, 52 and $23 \%$, which was lower, respectively, by 32, 17 and $39 \%$ than in control (see Fig. 1).

At low temperatures $\left(3^{\circ} \mathrm{C}\right)$, the germination of seeds, in addition to dill, celery and lovage, was observed in coriander, and at varying temperatures the seeds of all the studied crops did germinate. With increasing time of incubation, the proportion of germinated seeds was usually reduced by $12-100 \%$, which was especially noticeable in celery, lovage and coriander.

The increased time of seed incubation in the extract resulted in a reduced temperature coefficient $\left(\mathrm{Q}_{10}\right)$ for the embryo growth rate at different temperature settings for germination (Fig. 2).

Correlation and regression analyses showed that the temperature coefficient was strongly negatively correlated with the incubation time $(r=-0,700)$ which can be described using the following regression equation $\mathrm{y}=1.37-0.04 \mathrm{x}$.

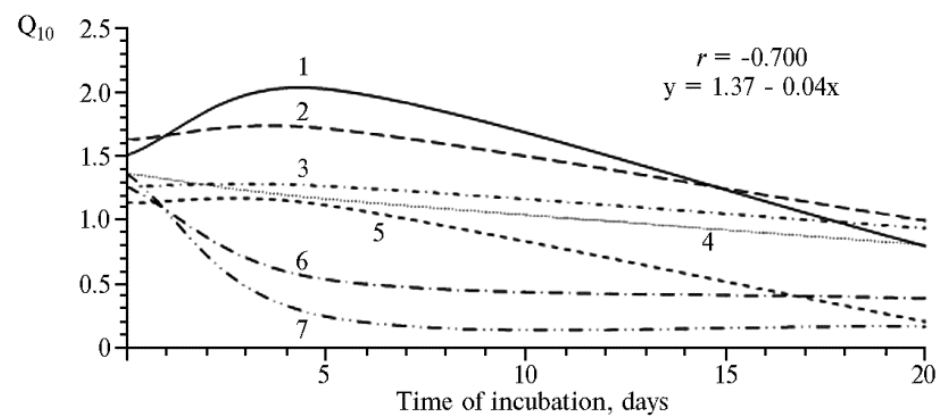

Fig. 2. Changes in the temperature coefficient $\left(\mathrm{Q}_{10}\right)$ for the embryo growth rate in the Umbelliferae vegetable family depending on time of incubation in the $15 \%$ extract of dill seeds: 1 - carrot (Daucus carota L.) Rogneda var.; 2 - root parsley (Petroselinum crispum (Mill.) Nyman ex A.W. Hill. Lyubasha var.; 3 - lovage (Levisticum officinale W.D.J. Koch Don Zhuan var.; 4 - dill (Anethum graveolens L.) Kentavr var.; 5 - coriander (Coriandrum sativum L.) Yantar' var.; 6 - parsnip (Pastinaca sativa L.) Kulinar var.; 7 - celery Apium graveolens L.) Kupidon var. (lab experiments).

Dill was characterized by gradual reduction of the temperature coeffi- 
cient when the time of stress exposure was increased: $\mathrm{Q}_{10}$ was 1.37 in the control and gradually decreased to 0.81 after exposure to high temperatures within 5 and 20 days. In root parsley and carrots, an increase in $\mathrm{Q}_{10}$ occurred (1.63-1.51 in control, and 1.72-2.03 when affected by incubation), although further influence of the allelopathic stress resulted in a decrease of the temperature coefficient. In celery, coriander and parsnip, a prolonged stress resulted in drastically reduced temperature coefficient. The temperature coefficient for the embryo growth rate was least affected by the incubation time in lovage, although some reduction of the $\mathrm{Q}_{10}$ value was observed.

Therefore, we have established the apparent manifestation of allelopathic activity of the dill seed extract which may have a significant effect on seed germination of the Umbelliferae family crops and changes of the embryo linear dimensions. Seed exposure to low temperature post incubation contributes to the restoration of these processes. Analysis of the effects caused by allelopathic factor and temperature evidenced that the inhibition of seed germination under the influence of dill seed extract was due to the dormancy phenomenon.

\section{REFEREN CES}

1. Grodzins ki i A.M. Allelopatiya rastenii i pochvoutomlenie [Allelopathy of plant and soil exhaustion]. Kiev, 1991 (in Russ.).

2. Rice E.L., Li n C.Y., H u a ng C.Y. Effects of decaying rice straw on growth and nitrogen fixation of a blue green alga. Bot. Bull. Acad. Sin., 1980, 21: 111-117.

3. Pickett J.A., B irkett M.A., B las sioli-Moraes M.C., B ruce T.J.A., Cha mb e rlain K., Gordon-Weeks R., Mat thes M.C., Napi e r J.A., S mart L.E., Wa d ha ms L.J., Wo od cock C.M. Cis-Jasmone as allelopathic agent in inducing plant defence. Allelopathy Journal, 2007, 19: 109-117.

4. H a rb o r n e J.B. Chemical signals in the ecosystem. Ann. Bot., 1987, 60: 39-57.

5. Ei n he 11 ig F.A. Allelopathy: current status and future goals. In: Allelopathy: Organisms, processes, and applications. Washington, 1995.

6. Si e mens D.H., G a r ner S.H., M itche 11 - O ld s T., Callaw ay R.M. Cost of defense in the context of plant competition: Brassica rapa may grow and defend. Ecology, 2002, 83: 505-517 (doi: 10.2307/2680031).

7. Murrel1 C., Gerber E., Krebs C., Parepa M., Schaffner U., Bossdorf O. Invasive knotweed affects native plants through allelopathy. Amer. J. Bot., 2011, 98: 38-43 (doi: 10.3732/ajb.1000135).

8. Blair A.C., Weston L.A., Nissen S.J., Brunk G.R., Hufbauer R.A. The importance of analytical techniques in allelopathy studies with the reported allelochemical catechin as an example. Biol. Invasions, 2008, 11: 325-332 (doi: 10.1007/s10530-008-9250-1).

9. Popovici J., Bertrand C., Jacque moud D., Bellvert F., Fernandez M.P., C o m t e G. An allelochemical from Myrica gale with strong phytotoxic activity against highly invasive Fallopia $\times$ bohemica taxa. Molecules, 2011, 16: 2323-2333 (doi: 10.3390/molecules16032323).

10. Alsaadawi I.S., Khaliq A., Lahmod N.R., Matloob A. Weed management in broad bean (Vicia faba L.) through allelopathic Sorghum bicolor (L.). Allelopathy Journal, 2013, 32(2): 203-212.

11. Reigosa M.J., Gonzalez L., S anchez-Moreiras A., Duran B., Puime D. Comparison of physiological effects of allelochemicals and commercial herbicides. Allelopathy Journal, 2001, 8: 211-220.

12. Oracz K., Bailly C., Gniazdowska A., Come D., Corbineau F., Bogat e k R. Induction of oxidative stress by sunflower phytotoxins in germinating mustard seeds. $J$. Chem. Ecol., 2007, 33: 251-264 (doi: 10.1007/s10886-006-9222-9).

13. Oracz K., Voegele A., Tarkowska D., J a c que moud D. Myrigalone A inhibits Lepidium sativum seed germination by interference with gibberellin metabolism and apoplastic superoxide production required for embryo extension growth and endosperm rupture. Plant Cell Physiol., 2012, 53: 81-95 (doi: 10.1093/pcp/pcr124).

14. Reig os a M.J., S o ut o X.C., Gonzalez L. Effect of phenolic compounds on the germination of six weeds species. Plant Growth Regul., 1999, 28: 83-88.

15. Ala m S.M., Ala S.A., Azmi A.R., Khan M.R., A n s a ri R. Allelopathy and its role in agriculture. Journal of Biological Sciences, 2001, 1: 308-315 (doi: 10.3923/jbs.2001.308.315).

16. C o o k C.E., Wh i chard L.P., T u r n e r B., Wa 11 M.E., Eg le y G.H. Germination of witch weed (Striga lutea Lour): isolation and properties of a potent stimulant. Science, 1966, 154: 1189-1190.

17. Xi e X., Y o n e y m a K., Y o n e y m a K. The strigolactone story. Annu. Rev. Phytopathol., 
2010, 48: 93-117 (doi: 10.1146/annurev-phyto-073009-114453).

18. Toh S., Kami ya Y., Kaw a k mi N., N a mbara E., M c Court P. Thermoinhibition uncovers a role for strigolactones in Arabidopsis seed germination. Plant Cell Physiol., 2012, 53: 107-117 (doi: 10.1093/pcp/pcr176).

19. Bukharov A.F., B a l e e v D.N. Izvestiya OGAU (Orenburg), 2012, 4(36): 225-229 (in Russ.).

20. L e m a n $\mathrm{n}$ E., A i k h e le F. Fiziologiya prorastaniya semyan zlakov [Physiology of seed germination in cereals]. Moscow, 1936 (in Russ.).

21. B u kharov A.F., B a le e v D.N., B u k ha rova A.R. Kinetika prorastaniya semyan. Sistema metodov i parametrov (uchebno-metodicheskoe posobie) [Kinetics of seed germination: methods and parameters]. M., 2016 (in Russ.).

22. Thoms o n A.J., E $1-\mathrm{K}$ a s s a b y Y.A. Interpretation of seed-germination parameters. New Forests, 1993, 7: 123-132 (doi: 10.1007/BF00034195).

23. Ha y a s i E., A o y a m a N., S t i 11 D.W. Quantitative trait loci associated with lettuce seed germination under different temperature and light environments. Genome, 2008, 51: 928-947 (doi: 10.1139/G08-077).

24. Kazmi R.H., Khan N., Wille ms L.A.J., Van Heusden A.W., Ligterink W., Hilhorst H.W.M. Complex genetics controls natural variation among seed quality phenotypes in a recombinant inbred population of an interspecific cross between Solanum lycopersicum $\times$ Solanum pimpinellifolium. Plant, Cell and Environment, 2012, 35: 929-951 (doi: 10.1111/j.13653040.2011.02463.x).

25. B e w le y J.D., B l a c k M. The physiology and biochemistry of seeds. V. 2. Springer-Verlag, Berlin, 1982.

26. Grushvitski i I.V., Agnaeva E.Ya., Kuzin a E.F. Botanicheskii zhurnal, 1963, 48(10): 1484-1489 (in Russ.).

27. B a le e v D.N., B u k h a rov A.F. Ovoshchi Rossii, 2012, 1(14): 54-60 (in Russ.).

28. K o r y u m E.L. Tsitoembriologiya semeistva zontichnykh [Cytoembriology of Umbelliferae family]. Kiev, 1967 (in Russ.).

29. B a s k i n C.C., B a s k i n J.M. Seeds: ecology, biogeography, and evolution of dormancy and germination. Academic Press, NY, 1998.

30. Probert R.J. The role of temperature in germination ecophysiology. In: Seeds: the ecology of regeneration in plant communities. M. Fenner (ed.). CAB International, Wallingford, 1992: 285-325.

31. B a tlla D., B e n e c h-A rnold R.L. A quantitative analysis of dormancy loss dynamics in Polygonum aviculare L. seeds: development of a thermal time model based on changes in seed population thermal parameters. Seed Sci. Res., 2003, 13: 55-68 (doi: 10.1079/SSR2002124).

32. Nikola eva M.G., Ly a guzova I.V., Pozdova L.M. Biologiya semyan [Seed biology]. St. Petersburg, 1999 (in Russ.).

33. O $\mathrm{v} \mathrm{ch}$ a rov K.E. Fiziologicheskie osnovy vskhozhesti semyan [Physiology of seed germination]. Moscow, 1969 (in Russ.).

\section{Science Events \\ INTERNATIONAL CROP SCIENCE CONFERENCE \& EXHIBITION \\ (10-11 November 2016, Goa, India)}

Organization: Pesticides Manufacturers \& Formulators Association of India

ICSC \& $\mathrm{E}$ is an exclusive event for agri inputs and allied industry. The conference will focus on Global Market, Formulation Technology Innovations, BIOSTIMULANTS, PLANT HEALTH, NUTRITION \& CROP ENHANCEMENT, seeds and fertilizers. There will be 60 exhibitions both from India and across the globe. Factory visit and farm visit will be arranged for the participants. World renowned experts will present on the subjects.

Information: http://www.globaleventslist.elsevier.com/events/2016/11/international-crop-science-conference-exhibition/ 